\title{
Low Temperature Engineering for Sea Protection
}

\section{BT Marinyuk*, MS Ugolnikova and GA Morozova}

Department of Low Temperatures Engineering, Russia

Received: 眥 November 10, 2018; Published: 制 November 15, 2018

*Corresponding author: BT Marinyuk, Department of Low Temperatures Engineering, Russia

\section{Mini Review}

Cryogenics is an applying science which deals with low temperatures. Ed this branch of engineering is of a great importance in the field of sea preservation from different substances, which are not friendly with sea environment. There are at least three brunches, where low temperature engineering brings the greatest help to support sea ecology when oil is digging out on the sea shelf. The first item is a creation of sea oil digging platform on the bases of water ice technology [1-3]. Water is a good and natural friendly substance. When it is frozen down to an ice state, one gets quite a solid and durable material, like concrete, if it is kept at low temperatures. Generation of low temperatures at the sea oil platform is not a hard problem even without electric energy supply. So if a vertical metal tube is filled with water ice it turns into a support column of the sea platform, strong and reliable. The bottom of it is frozen down to the soil shelf with the help refrigeration unit. This method reduces the time of constructing as well as simplifies dismantling works with lowering costs when the period of platform operating is over. The columns supporters do not remain where they are installed, but are transported on the new place and can be used many times.

The second item. Cryogenic fluids like nitrogen have the ability to protect the platform communications from oil leakage through forming of water ice cover on the spot where communication tube gives oil leakage. The process of ice covering is developed with a great rate and depends on the tube wall surface $\mathrm{T}_{\mathrm{s}}$, water temperature $\mathrm{T}_{w}$ and heat transfer coefficient from water to the surface $\alpha_{w}$.

At the first approach the growth rate of ice cover $\xi^{\prime}$ can be determinate by agnation

$$
\xi^{\prime}=-\frac{\alpha_{w}\left(T_{w}-T_{p h}\right)}{\rho^{L}}+\frac{\left[\alpha_{w}\left(T_{w}-T_{p h}\right)\right]^{2} \tau-\lambda \rho L\left(T_{s}-273\right)}{\lambda \rho L \sqrt{\left[\frac{\alpha_{w}\left(T_{w}-T_{p h}\right) \tau}{\lambda}\right]^{2}-\frac{2 \rho L\left(T_{s}-273\right) \tau}{\lambda}}}
$$

$\rho$ - ice density, $\mathrm{kg} / \mathrm{m}^{3}$

$\mathrm{L}$ - heat of phase changes (freezing of water into ice), Dj/kg
Tph - temperature of phase change, $\mathrm{K}$

$\lambda$ - heat conductivity of water ice at $0^{\circ} \mathrm{C}, \mathrm{W} /(\mathrm{m} \cdot \mathrm{K})$

$\tau$ - times, $s$

The third item. Oil digging platform is an object where fire casualties may occur. Liquid nitrogen being preserved in a cryogenic tank is an efficient fire extinguisher. Water ice formation on the low temperature surface is also actual for underwater works, connected with extraction of subjects from the sea bottom. A lot of shell garbage pollute the marine environment. There are a lot of metal barrels, some of them contain chemically dangerous substances.

As they are in a long term location in a sea water the corrosion has damaged the walls. The latter excludes a mechanical capturing them for lifting to the sea surface and transporting for utilization on the ashore. So, the low temperature engineering gives an alternative to the mechanical method. New approach requires no mechanical contacts with the subject. The procedure of contactless capturing implies that heat insulated tube is moved out from cryogenic tank and immersed at the subject depth. It is suspended above the surface of the subject but without contacting it, the gap is $50-100 \mathrm{~mm}$. Then cryogenic fills the tube's volume down to the bottom, which looks like flat metal disk. Ice is formed on the surface of the flat disk and gap between it and the shell surface is turned into an ice bridge connecting both sides. Gradually ice is covering the damaged shell and strengthen it. Then the heat insulated tube with cryogenic tank are lifted from the depth of the sea water and are carried to the shore. This method requires no manual efforts, the works are implemented by a camera visualization.

\section{References}

1. Marinyuk BT, Ugolnikova MA (2017) The influence of water ice conductivity on its formation. MOJ Eco Environ Sci 2(2): 57-59.

2. Marinyuk BT (2015) The calculation of heat transfer in the apparatus and the low-temperature cooling systems. «Mashinostroenie» (Publishing house), Moscow.

3. Marinyuk BT, Ugolnikova MA (2018) Precluding oil leakage from oil ship tankers under mechanical damage. MOJ Eco Environ Sci 3(3): 212-214. 
(C) This work is licensed under Creative

To Submit Your Article Click Here: Submit Article

DOI: $10.32474 /$ MAOPS.2018.02.000138

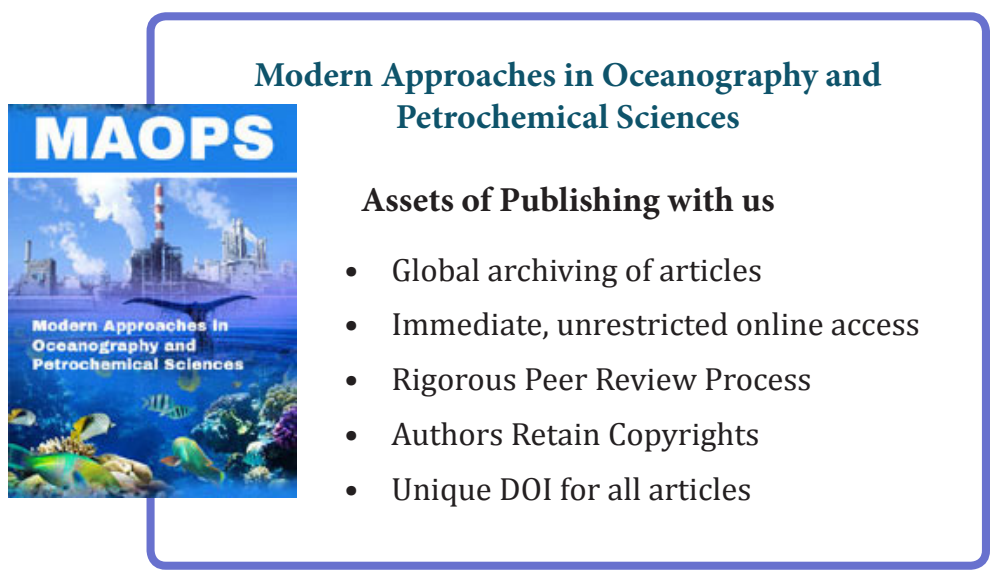

